\title{
Ablation of Chronic Total Occlusions Using Kilohertz-Frequency Mechanical Vibrations in Minimally Invasive Angioplasty Procedures.
}

\author{
Garrett McGuinness \\ Dublin City University \\ Mark Wylie \\ Technological University Dublin, mark.wylie@tudublin.ie \\ Graham Gavin \\ Technological University Dublin, graham.gavin@tudublin.ie
}

Follow this and additional works at: https://arrow.tudublin.ie/biodevart

Part of the Biomedical Engineering and Bioengineering Commons

\section{Recommended Citation 38 no.6, pp.511-31. doi:10.1615/CritRevBiomedEng.v38.i6.20 \\ This Article is brought to you for free and open access by the Biomedical Devices and Assistive Technology Research Group at ARROW@TU Dublin. It has been accepted for inclusion in Articles by an authorized administrator of ARROW@TU Dublin. For more information, please contact arrow.admin@tudublin.ie, aisling.coyne@tudublin.ie,gerard.connolly@tudublin.ie. Funder: N/A}

McGuinness, G., Wylie, M., \& Graham, G. (2010) Ablation of Chronic Total Occlusions Using KilohertzFrequency Mechanical Vibrations in Minimally Invasive Angioplasty Procedures. Crit Rev Biomed Eng. vol.

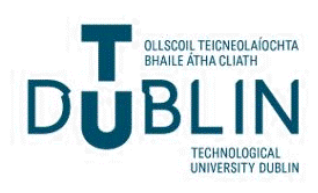




\title{
High Frequency Mechanical Ablation of Chronic Total Occlusions in Minimally Invasive Angioplasty Procedures
}

\author{
G.B. McGuinness ${ }^{1 *}$, M.P. Wylie ${ }^{2,3}$, G.P.Gavin ${ }^{2,3}$ \\ ${ }^{1}$ School of Mechanical and Manufacturing Engineering, \\ Dublin City University, \\ Dublin 9, \\ Ireland \\ garrett.mcguinness@dcu.ie \\ ${ }^{2}$ School of Manufacturing and Design Engineering \\ Dublin Institute of Technology, \\ Bolton Street, \\ Dublin 1, \\ Ireland \\ ${ }^{3}$ Biomedical Devices and Assistive Technologies Research Group \\ Dublin Institute of Technology \\ Bolton Street, \\ Dublin 1, \\ Ireland
}

*Author to whom correspond should be addressed/ 


\begin{abstract}
Certain minimally invasive cardiology procedures, such as balloon angioplasty and stent implantation, critically require that the site of an arterial blockage be crossed by an intraluminal guidewire. Plaques resulting in near or totally occluded arteries are known as chronic total occlusions (CTOs), and crossing them with conventional guidewires is a significant challenge. Among the most promising proposed solutions is the delivery of high power, low frequency ultrasonic vibrations to the occlusion site via an intraluminal wire waveguide. The vibrating distal-tip of the ultrasound wire waveguide is used to transmit energy to the surrounding plaques, tissues and fluids in order to ablate or weaken atherosclerotic plaque. Potential mechanisms of interaction with the plaque and adjacent fluids identified in the literature include; (i) direct contact with the waveguide distal tip, (ii) subcavitational acoustic fluid pressure fluctuations, (iii) cavitation, and (iv) acoustic streaming. This article will summarize developments in this area over more than two decades, describing experimental methods for device performance characterization, preclinical tests, early clinical investigations and, later, full clinical trials. The article will also review theoretical foundations, and numerical models suitable for device design and analysis. Finally, important issues for future research and for the development of this technology will be considered.
\end{abstract}




\section{INTRODUCTION}

Interventions such as Percutaneous Transluminal Coronary Angioplasty (PTCA) and stenting are now widely used to restore blood flow through blocked or partially blocked arteries. These procedures involve threading a catheter and balloon assembly along a guidewire to the blockage site via the arterial lumen. A guidewire is a thin wire with distal geometry specifically designed to facilitate navigation through tortuous and branching vessels in order to establish a viable path to and across the site of a blockage. It acts as a guiderail for catheters to facilitate the positioning of balloon/stent assemblies prior to deployment. Once in position, the balloon is expanded to disrupt and displace the plaque in order to restore blood flow through the artery. A wire scaffolding structure, known as a stent, may also be expanded by the action of the balloon, and its purpose is to hold the artery open, preventing recoil once the balloon is removed.

A major prerequisite for the use of these interventional procedures, therefore, is the ability to first traverse the lesion with an intraluminal guidewire. Depending on the nature of the blockage, this may be extremely difficult or impossible with conventional guidewires. Such cases are often characterised as chronic total occlusions (CTOs), referring to total closure of the vessel. Several novel approaches to overcome this problem have been proposed. Among the most promising is a technology involving the delivery of high power, low frequency ultrasonic vibrations to the total occlusion site via an intraluminal wire waveguide in order to assist the progression of the guidewire across the lesion by a process of plaque ablation or disintegration. 


\section{ATHEROSCLEROTIC PLAQUES}

\section{II.A Atherogenesis}

Atherosclerosis is a thickening of the arterial medial layer which affects the artery by altering conduit function and reducing blood flow downstream. There are numerous hypotheses describing the origin and progression of the disease, which are beyond the scope of this review. It is known to be a time-dependent process with varying stages of severity (1-3), as confirmed by extensive autopsy studies(4). The progression of atherosclerosis can be broadly classified into three stages; the fatty streak, the fibroatheromatous plaque and the complicated lesion $(5,6)$.

Initially, a fatty streak formed by lipid deposits appears on the intimal surface of arteries but does not always progress into a fibroatheromatous plaque $(5,6)$. The fibroatheromatous plaque consists of a necrotic plaque core that is surrounded on one side by the underlying arterial wall and bounded on the other by a plaque cap as shown in Figure 1(5).

The fibroatheromatous plaque is a clearly raised lesion and has a plaque core that consists of a mix of collagen fibres, soft lipid and calcified materials and is often known as a fibrous core(6). The lesions tend to progress further and are often associated with events such as the plaque core rupturing that can lead to haemorrhaging or clotting resulting in further loss or complete loss of lumen diameter as shown in Figure 1(5).

For characterization of the degree of progression of atherosclerosis, some of the minor classifications are; superficial calcified nodules, yellow colour (high risk rupture), inter plaque haemorrhaging, endothelial dysfunction and remodelling. Some of the major classifications for this disease include; active inflammation (macrophage accumulation); thin cap with large lipid core; endothelial denudation; and fissured plaque caps. 
There are 6 or so histological classifications described by Stary et al(7) which characterise the pathogenesis of an atherosclerotic lesion.

Initial lesions (I - III) - not detectable by angiography(7)

- Type I: Lesion contains enough atherogenic lipoproteins to initiate the formation of macrophages and macrophage foam cells.

- Type II: Lesions have appearance of fatty streak, lesion consists primarily of macrophages foam cells and lipid laden smooth muscle cells.

- Type III: Formation of extracellular lipid droplets and other particles that prevent the coherence of some intimal smooth muscle cells.

Advanced lesions: (IV - VI) (7)

- Type IV: Atheroma is formed, lipid core formation by the gathering of the lipid droplets/pools, lesion has potential to be symptomatic. Initially is often an eccentric lesion.

- Type V: Often have lipid core and may also contain fibrous connective tissue, a fibroatheroma lesion.

- Type Va: May be multilayered, several lipid cores separated by fibrous layers.

- Type $\mathrm{Vb}$ : These lesions are largely calcified.

- Type VI: Lipid core, thick layers of fibrous tissue, with possibility of fissure, hematoma and thrombus. These complicated lesions represent much higher morbidity and mortality than any other previous lesions. 
Of particular interest are the complicated calcified plaques that have a plaque core and cap that are primarily composed of calcified minerals and tough collagen fibres(5). These fall under the classification of advanced lesions, partly due to the time they take to develop as they tend to occur later in the lesion progression. They are closely associated with chronic total occlusions and the success rate with standard procedures involving the mechanical loading of the lesion tend to be lower as the rigidity and stiffness of the calcified material and tough collagen fibres can resist these applied loads(5).

\section{II.B Mechanical Characteristics of Atherosclerotic Plaques}

Knowledge of the mechanical and physical properties of various plaques and of the healthy arterial wall is of great benefit when developing methods and devices to treat specific lesion types. Plaque mechanical properties are largely responsible for problems experienced with the use of standard interventional procedures for chronic total occlusions. As biological materials, these plaques exhibit complex properties in response to mechanical compression or indentation.

Specific plaque mechanical properties vary depending on the pathogenesis of the lesion. Early stages of the disease exhibit time dependent behaviour under constant mechanical loading (i.e. viscoelastic behaviour). Over time, the plaques often exhibit non-linear and inelastic mechanical behaviour. Stress-strain curves for loading and unloading of lesions also exhibit hysteresis.

As time progresses, the lesion can become harder and more brittle. From an experimental perspective and given the variability in properties and composition, it is challenging to study the mechanical composition of lesions, since they only occur in humans, although some lesions types can be artificially induced in animals. 
Some studies have highlighted the mechanical properties of the various types of atherosclerotic lesions. Loree et al excised specimens in the circumferential direction and classified them histologically as cellular (12 samples), hypocellular (9 samples) or calcified (5 samples)(8). The hypocellular plaques were found, on average, to be 1-2 times stiffer than cellular plaques and calcified plaques were $4-5$ times stiffer than cellular plaques.

Topoleski and Salunke(9) also report the mechanical behaviour of various plaque types as well as contiguous arterial tissue. Segments of human aortoiliac artery were excised during autopsy and atherosclerotic lesions (plaque cap and core) removed and cut into small specimens. A pathologist classified each specimen as calcified (hard), fibrous (medium) or atheromatous core (soft). The samples were subjected to uniaxial compression tests, compressing samples in the radial direction. The plaque response was indeed non-linear and the plaques could be characterised into three distinct mechanical behaviour patterns. A wide variation in the properties of the plaque types was clearly seen, with the hard calcified and fibrous plaques (containing some calcium) showing a distinct behaviour, with a considerably stiffer response under compression than the medium and soft plaques and the healthy arterial tissue.

\section{II.C Complications Associated with Percutaneous Coronary Interventions}

The American College of Cardiology and American Heart Association has developed a widely used classification system for coronary atherosclerotic lesions, treatment options and the likelihood of successful treatment.

- Type A, are most ideal for PTCA, they are less than $10 \mathrm{~mm}$ long and concentric with thrombus absent, drug treatment may be preferable. 
- Type B, lesions are intermediate with $100 \%$ occlusion less than 3 months, $10-20 \mathrm{~mm}$ long, eccentric with some thrombus present.

- Type $\mathrm{C}$, are the most challenging. They are larger than $20 \mathrm{~mm}$ and $100 \%$ occluded for longer than 3 months(10).

Early stage lesions can be treated by the typical PTCA. However CTOs are challenging as they do not lend themselves to be accessed by the guidewire. Guidewire access and ability to cross the lesion is critical to the success of standard dilations procedures and has been reported to be the key success indicator in $80 \%$ of cases(11).

In many cases, traditional guidewires are not stiff enough to transverse the tough fibrous cap and, indeed, the higher forces applied could carry an associated risk of arterial perforation. Therefore, bypass graft surgery is often required, which is a more invasive and less desirable treatment option. CTOs are a significant cause for coronary bypass graft surgery referral (12). Not only are there problems traversing the $\mathrm{CTO}$, but other issues lie with safe re-entry into the target lumen. CTOs are known to have micro-vessels which are formed within the organising thrombi (a result of endothelial cells invading the fibrin lattice) that may hinder successful dilation by angioplasty(13).

More advanced lesions can be unstable and potentially hazardous. Death and myocardial infarction may occur during $\mathrm{CTO}$ angioplasty by shearing off the collateral circulation, thrombus formation, perforation, arrhythmia or damaging the proximal epicardial coronary artery or proximal side branches(14).

Chronic total occlusion of a coronary artery is usually defined as "an obstruction of a native coronary artery for greater than 30 days with no luminal continuity and with thrombolysis in myocardial infarction (TIMI) flow grade 0 or 1" (15). CTOs are generally found in small arteries 
such as those in the coronary artery tree. Chronic total occlusion of the right coronary artery is identified in approximately $20 \%$ of angioplasty patients, and angioplasty of the CTO is attempted in between $10-15 \%$ of all cases(16). However, standard techniques, using contemporary guidewires, are unsuccessful in approximately $20 \%$ of these cases $(14,17)$. Due to the difficulty in dealing with CTOs, a number of patients with these types of lesions are referred to by-pass surgery. Success rates in CTOs have steadily increased over the last 15 years because of greater operator experience, improvements in equipment, and procedural techniques. However, minimally invasive procedures on these types of lesions are the most likely to fail. The majority of failures are due to the inability to successfully pass a guidewire across the lesion (89\%)(17). The ability to $\operatorname{cros}\{\{\}\}$ s the lesion with a guidewire is the main determinant of interventional success and if this cannot be achieved, dilation devices, such as balloon angioplasty and stents, cannot gain access to the lesion site to reopen the blockage.

Even if guidewire access can be achieved, calcifications can lead to a requirement for higher balloon pressures during dilation procedures. Siegel et al expressed concern regarding a link between high balloon inflation pressures and deep vessel injury and acute procedural complications, known as barotraumas, all resulting in greater localised damage and higher restenosis rates(18).

While plaques can develop around the entire lumen structure, resulting in a concentric lesion, progression is often eccentric (19-21). Calcified eccentric lesions pose further complications as during dilation procedures the rigid calcified side of the artery can potentially remain non-dilated while the healthy and often thinner side of the arterial wall over-dilates, meaning that mechanical dilation-based interventions with eccentric lesions can be less effective(19). Thus, standard interventional procedures work best with concentric lesions as the pressure is divided relatively 
evenly over the lesion. However, dilation of eccentric lesions can be problematic because less diseased walls becoming overstretched, increasing the risk of cell necrosis and of tearing, and also increasing the risk of restenosis.

Interventional procedures for these applications should ideally incorporate a means of establishing access to the site by navigating the vascular structure, be capable of disrupting total blockages due to plaque or thrombus so that a guidewire can be advanced, and also be able to selectively damage calcified material while leaving healthy tissue largely unaffected.

\section{II.D Recent Clinical Progress}

A conventional approach to the problem involves the design of specialized passive guidewires. The attributes of typical commercial devices are summarized in Table 1, and are more comprehensively reviewed elsewhere(22). Godino et al list the critical characteristics of a guidewire as "tip load, tip stiffness guidewire flexibility, ability to shape, shaping memory, shaft support, torque transmission, trackability and resistance to tracking of the wire within the occlusion"(22). The majority of current guidewires have a main shaft diameter of $0.35 \mathrm{~mm}$ or less. The tips vary from $0.2-0.35 \mathrm{~mm}$ in diameter, depending on the guidewire. Guidewires fall into two classifications; Hydrophilic, which give better tactile feedback, and Non-hydrophilic which have lower resistance and better maneuverability (22). Guidewires are also classified as soft, intermediate or stiff. Soft wires are normally used for advancement of the catheter and crossing occlusions with small lumens. Intermediate wires are used for recently occluded lesions or tortuous vessels and stiff wires are used for advancing through CTOs. The suggested method for crossing CTOs is to use a soft or intermediate wire to explore the area. A stiffer guidewire can then be used to cross the proximal cap if needed. An even stiffer guidewire can again be 
used, if necessary, to cross the CTO and penetrate the distal cap. After the occlusion has been crossed the stiff guidewire is then replaced by a soft guidewire(22).

Lefevre(23) reports that, during procedures involving CTOs, crossing lesions may take up to 35 minutes and, with the possibility of guidewire changeovers, entire procedures may take 1.5 hours. This has implications for the cost of procedures. A soft guidewire with the capability of crossing CTOs would offer major advantages, reducing the need for changing wires, and therefore reducing the time required for crossing CTOs and increasing the likelihood of success for the procedure.

As an alternative approach, therapeutic ultrasound transmitted via wire waveguides has long been identified as a technology with the potential to disrupt atherosclerotic lesions with mechanical vibrations transmitted via long, low profile, flexible superelastic wire waveguides. Several prototype devices have been developed in an attempt to meet this challenge, including a recent $20 \mathrm{kHz}$ ultrasound wire waveguide clinical device, which delivers high power low frequency intravascular acoustic energy to the sites of chronic total occlusions(24).

In early 2005, Flowcardia ${ }^{\mathrm{TM}}$ Inc., (Sunnyvale, California, USA), received approval to market this ultrasonic waveguide (the Crosser(C) System) in the European Union for the treatment of chronic total occlusions following failure to cross by conventional guidewire techniques(24), and the device was granted FDA approval in 2007.

The device, based on a monorail concept, is approved specifically for use on chronic total occlusions (CTOs). The system used is run at a frequency of approximately $20 \mathrm{kHz}$ and with a working length of $146 \mathrm{~cm}$. The ultrasound is transmitted via a nickel-titanium wire waveguide to a $1 \mathrm{~mm}$ diameter stainless steel tip. Apart from the tip, the ultrasound wire and guidewire are all 
housed in a $6 \mathrm{~F}$ catheter, which acts as an irrigation system. The system works by moving a guidewire to the point of the lesion and then the stainless steel tip is advanced over the guidewire, fragmenting the lesion as it is pushed forward.

In one trial, 55 CTO's in 53 patients were treated using the system. The device showed a success rate of $76 \%$ with no major cardiac events or coronary perforation(25). In a second study with 30 lesions in 28 patients success was achieved with $63 \%$ of procedures(24). However there was one guidewire perforation with no serious adverse effects and one peri-procedural myocardial infarction.

\section{Fundamentals of High Power, Low Frequency Therapeutic Ultrasound Angioplasty}

\section{III.A Background}

In the present context, therapeutic ultrasound refers to the use of high-amplitude lowfrequency ultrasound in clinical interventions (26). The mechanical effect this form of ultrasound has on biological tissues was first noted by Conte and de Lorenzi (cited in Atar et al(27)) and its effectiveness is based on the fact that at the right combination of frequency and amplitude inelastic rigid tissue is vigorously disrupted while elastic tissue can absorb the energy $(28,29)$.

It was therefore conceived that this form of energy may be useful in the treatment of cardiovascular disease and could potentially have advantages over standard dilation procedures in the targeting of specific lesions, especially complicated rigid calcified and fibrous plaques(26).

Development and testing of experimental devices began as early as the 1970s but were extremely limited for practical use. Sobbe et al (30) showed that ultrasound delivered through a 
large diameter wire probe resulted in a longitudinally vibrating distal-tip that had the effect of disrupting blood clots in animals.

During the mid-1980s particular design issues were addressed by two groups, headed by Siegel and by Rosenschein, with the goal of making an actual working prototype for initial clinical testing and potentially for use in trials. No specific design issues appear in the literature and the majority of work focuses on the end clinical results. Some general information is reported and is included in this review(31-33).

Both teams based their design efforts on the system developed by Sobbe et al(30) delivering the ultrasonic waves to the lesion via a wire waveguide. This sets up longitudinal stress waves and a longitudinal peak-to-peak displacement at the distal-tip of the wire waveguide with the potential to disrupt both lesions and clots.

\section{III.B Ultrasound generation}

In order to displace the distal-tip a wire at the frequencies and high amplitude displacements required to cause disruption to lesions a source capable of delivering these ultrasonic displacements was required. Both Siegel et al (33) and Rosenschein et al(31,32) describe the use of a piezoelectric transducer as a source for the ultrasound.

The piezoelectric effect is a property of certain classes of crystalline materials including natural crystals of Quartz, Rochelle Salt and Tourmaline plus manufactured ceramics such as Barium Titanate and Lead Zirconate Titanates (PZT). When a mechanical pressure is applied to these materials a voltage is produced proportional to the pressure applied. Conversely, when a voltage is applied the structure changes shape; acting as an electromechanical transducer. These shape changes are usually very small, usually in the order of a few microns. 
Dynamic voltages can also be applied which result in a dynamic displacement or shape change in the material. In this arrangement the material behaves very much like a mechanical system with resonant frequency characteristics. The transducer's output will be at a maximum at the first resonant frequency, a characteristic of the material and geometric configuration. Using a stack arrangement as shown in Figure 2a, mechanical amplitudes of vibration of $0-5 \mu \mathrm{m}$ peakto-peak at frequencies less than $100 \mathrm{kHz}$ can be achieved. An ultrasonic generator provides the electrical source to drive the transducer at the resonant frequency of the piezoelectric stack (34, $35)$.

These types of transducer are used mostly for sonochemistry applications where agitation of chemical and biological samples is required. The frequencies and amplitudes discussed are chosen for their ability to cause cavitation, a desirable effect in processing chemical solutions. It is largely due to availability for this reason that transducers used for generating the ultrasound in intravascular therapeutic ultrasound have been adapted from sonochemistry applications (33). For sonochemistry and the generation of cavitation, the displacements (at the frequencies used) from the converter (transducer) are still too small for sample processing. An acoustic horn or waveguide is usually attached to the transducer to amplify the displacements.

Acoustic horns are solid metal rods that are designed to couple to the front-end mass of the converter. They achieve an increase in output displacement by two means. Firstly, their geometry is such that the input wave is compressed through a progressively smaller crosssectional area as it travels the length of the rod resulting in a larger displacement at the output. This can be clearly seen in both linear and exponentially tapered horns (35) [ 
Secondly, horns can be manufactured to resonate at the frequency of the ultrasonic converter. Stepped horns, as shown in Figure 2b, appear most useful for adaptation to the natural frequency of the driving transducer and are often easiest to manufacture (36).

In most practical applications a combination of both stepped and tapered sections are used in horn design. Horns are manufactured from materials that have high dynamic fatigue strength and low acoustic loss, such as titanium alloys. With a horn attached to the converter output amplitudes of vibration greater than $150 \mu \mathrm{m}$ can be achieved and at frequencies less than $100 \mathrm{kHz}$.

Acoustic horns, being of solid metal configuration, lack the flexibility necessary to navigate the tortuous vascular geometry. In order to deliver these ultrasonic peak-to-peak displacements over sufficient lengths and with the flexibility necessary in minimally invasive vascular surgery the idea of using wire waveguides was developed(30, 31, 33).

\section{III.C Minimal invasive delivery of ultrasound by wire waveguide}

Most of the initial work in the area was based on finding methods to deliver this form of ultrasound over waveguide lengths and small diameters capable of being used in surgical applications. While little detailed description of the exact design and construction methods is given, some general conclusions were drawn from early design and testing.

Rosenschein et al (32) described the use of a solid flexible aluminium transmission wire mechanically coupled to the acoustic horn. Details surrounding the coupling method were not included. Fischell et al describe the use of a solid 1.5F $\approx 0.5 \mathrm{~mm}$ diameter) titanium wire waveguide(37). This system also appears to have been used by Ariani et al (38) and Demer et al(28). 
These authors work, in general, detail the use of solid wires manufactured from aluminium, titanium or alloys of both to form the transmission member or wire waveguide to transmit the ultrasound from the acoustic horn to the lesion location. This ultrasonic transmission results in longitudinal displacements at the distal tip of the wire waveguide.

In addition both teams located a ball-tip or enlargement at the distal end of the wire. This increases the surface area in contact with the lesion and the surrounding fluid. Demer et al (28) describes the use of a $2.0 \mathrm{~mm}$ diameter ball-tip and Siegel et al (18) a $1.7 \mathrm{~mm}$ diameter ball-tip in conjunction with the wire waveguide.

\section{III.D Mechanical effect of wire waveguide tip displacement}

Atar et al (27) suggested that the ultrasonic longitudinal vibration of the wire waveguide distal-tip results in four major potentially disruptive events; direct contact ablation, pressure wave components, cavitation and acoustic micro-streaming and all these appear to be related to the distal-tip displacement amplitude, frequency and geometry(39-42). A diagram of the distal section of the wire waveguide and location of disruption mechanisms is shown in Figure 3.

\section{Direct contact ablation}

The oscillating distal-tip of the wire waveguide acts as an ultrasonic reciprocating microdrill. Research in ultrasonic micromachining has shown that it is associated with low material removal rates by microchipping, and is ideal for ablating brittle ceramic materials(43).

Direct contact between the oscillating tip and the plaque in the arterial lumen results in the fragmentation and ablation of the plaque into microscopic particles and is considered to be one of the major effects of ultrasound angioplasty(29). 
Also, it appears that due to the varying material properties of the plaques this form of fragmentation technique ablates less distensible rigid calcified and fibrous plaques faster than flexible material such as the healthy arterial wall tissue(31).

\section{Acoustic pressure waves and cavitation}

As a result of the direct contact between the oscillating distal-tip and surrounding fluid an oscillating acoustic pressure field, superimposed on the ambient pressure, is established around the distal-tip. Of particular interest is the fact that if the pressure amplitude is sufficiently high, cavitation in the fluid may occur.

Cavitation occurs when on the negative side of a pressure cycle, such as when the wire waveguide tip is retracting, with sufficient amplitude and frequency, suspended gas bubbles in the fluid, in channels within the tissue or trapped at solid interfaces expand and collapse with the generation of shock waves. Burdic (39) has suggested a simplified relationship between pressure and cavitation threshold, discussed in section IV.B. Cavitation is a potentially significant erosion event, undesirable in most acoustic applications but necessary in cavitation cleaning baths and sonochemistry $(39,40)$.

Yock and Fitzgerald(26) concluded that cavitation is a major contributing factor in the disruption of plaque and thrombus and that ultrasound ablation of lesions was only present above the cavitation threshold and that the rate of disintegration correlates with the amount of power delivered above this threshold.

Makin and Everbach(44) investigated the acoustic pressures developed by an ultrasonically vibrating wire waveguide submerged in a liquid with acoustic properties similar to blood. The experiment consisted of a $2.46 \mathrm{~mm}$ diameter spherical tipped wire oscillating in a 
cylinder of fluid (peripheral arterial phantom) at $22.5 \mathrm{kHz}$. Their experiment comprised of an ultrasonic emitter-receiver submerged in a tube within a $355 \mathrm{~mm}$ high acrylic tank with an internal diameter of $203 \mathrm{~mm}$. The tank was filled with water or a glycerine-water mix. The experiment was described as having a $355 \mathrm{~mm}$ high tank filled to $345 \mathrm{~mm}$ with fluid. Pressures were measured in the range of 12-250 $\mathrm{mm}$ from the vibrating tip using an acoustic hydrophone; measurements in the vicinity of the tip were restricted due to the limitations of their measuring equipment.

Their results demonstrate two important effects of the ultrasound in vivo:

1) While the authors were not able to directly measure pressures at the tip, 'cavitation activity’ was determined using a $20 \mathrm{MHz}$ focused transducer. They concluded that cavitation was evident and related to the distal-tip displacement and the distal tip geometry.

2) A standing wave in the acoustic domain of significant amplitude was also detected. They concluded that this standing wave was caused by an impedance mismatch between the liquid and the surrounding air. This is similar to the tissueair interface encountered in peripheral limbs in vivo, the result of reflection at the interface of layers/materials of different acoustic impedance. The sound power reflection coefficient is given as(45):

$$
\alpha=\left(\frac{\rho z_{2}-\rho z_{1}}{\rho z_{2}+\rho z_{1}}\right)^{-}
$$


where: $\alpha \mathrm{r}=$ sound power reflection coefficient

$\mathrm{c}=$ speed of sound in fluid medium

Assuming no energy loss, the reflection of the incident energy must correspond to a unity value of reflection coefficient. The speed of sound for air and blood/tissue was taken as $340 \mathrm{~m} / \mathrm{s}$ and $1580 \mathrm{~m} / \mathrm{s}$ respectively and with densities of $1.2 \mathrm{~kg} / \mathrm{m}^{3}$ and $1050 \mathrm{~kg} / \mathrm{m}^{3}$ respectively. Using equation 9 and the material properties shown, the sound power reflection can be calculated to be $99.9 \%$ at a tissue-air interface.

If the acoustic field produces sufficiently low pressures, cavitation may occur. This is considered to be the most powerful destructive mechanism of the ultrasonic ablation(46).

\section{Acoustic streaming}

Two general forms of fluid motion are set up around an oscillating sphere in a fluid. The first can be considered as the oscillatory fluid motion very close to the wall of the tip and, secondly, a unidirectional fluid motion in an external acoustic streaming layer as shown in Figure $4(40,41)$.

It is the combined presence of direct contact, acoustic pressure waves, cavitation and acoustic streaming that led investigators to believe that ultrasound delivered via a wire waveguide could disrupt arterial lesions and some analytical theory further describing these disruptive mechanisms is discussed later. 


\section{Theoretical Foundations}

This section focuses on the theoretical mechanics which govern the response of a uniform rod (waveguide) to a harmonic input displacement and also the fundamental principles of acoustic pressure field generation by an oscillating sphere (such as a distal ball-tip) in a fluid.

\section{IV.A Wire waveguide mechanics}

\section{Steady-state vibration of a uniform rod}

The steady-state analytical solution of motion for an undamped longitudinally vibrating rod, as shown in Figure 5, subjected to a sinusoidal input vibration motion of $u(t)=b \sin (\omega(t))$ is shown in Equation 1 (47). This is similar to the condition set up in ultrasound transmitted via a wire waveguide where the distal-tip of the acoustic horn applies a sinusoidal input of particular amplitude and frequency to the proximal end of the wire waveguide.

$$
u(x, t)=)\left(\cos \frac{\omega}{c}+\text { an } \frac{\omega}{c} \sin \frac{\omega}{c}\right) \sin \omega
$$

The steady-state amplitude of vibration at any point $(0 \leq x \leq l)$ can be determined although this is an undamped solution and therefore limited. The solution can also be used in the determination of resonant response.

The solution for the resonant response from Equation 1 is shown in Equation 2 where $f_{n}$ are the resonant frequencies of vibration for a thin rod of length $l$ and where the speed of sound (longitudinal) in the rod material is $c$.

$$
f_{n}=\frac{\imath c}{4 l} \quad n=1,3,5 \ldots
$$


Similarly, for a constant frequency Equation 3 gives us the lengths where resonance occurs $(\mathrm{n}=1,3,5,7 \ldots)$ and the lengths where non-resonance occurs $(\mathrm{n}=0,2,4,6,8 \ldots)$. This is more important to the ultrasound wire waveguide as the displacement input from the distal-tip of the acoustic horn is at a constant prescribed frequency determined the ultrasonic generator.

$$
l_{n}=\frac{n c}{4 f}
$$

The literature describes ultrasound transmission resulting in vibration of the distal-tip of the wire waveguide and that the presence of a spherical or near spherical ball-tip enhanced transmission to the fluid (44). An analytical solution for the pressure field developed in the fluid near to an oscillating sphere exists, proposed by Morse(42), as shown in Equation 4. Figure 6 illustrates the parameters appearing in this solution.

\section{IV.B Distal Tip Interactions}

\section{Acoustic pressure field around and oscillating sphere}

In this solution the maximum pressure at any point, $P_{\max }$, developed in the field surrounding an oscillating sphere can be determined.

$$
P_{\max }=? \pi \rho f^{2} d_{0} \times \frac{R^{2} \mid \cos \theta}{r^{2}}
$$

where $f$ is the frequency of oscillation, $d_{0}$ is the displacement amplitude of oscillation and $\rho$ is the fluid density. This solution shows that pressure amplitudes are at a maximum on the surface of the sphere and axially ahead of it.

\section{Cavitation}


From the pressure amplitude field it is possible to infer when and where cavitation is likely to occur. While the occurrence of cavitation is dependent on numerous factors such as the temperature and the amount of dissolved gas in the fluid, Burdic(39) suggests a simplified cavitation threshold intensity, as shown in Equation 5.

$$
T=\frac{P_{\max }^{2}}{2 \rho}
$$

According to Perkins(48) this threshold intensity for degassed water at room temperature is approximately between 2 and $3 \mathrm{Watts} / \mathrm{cm}^{2}$ in the frequency range of $20-30 \mathrm{kHz}$.

It is worth noting here, that the acoustic intensity required to cause cavitation increases significantly above a frequency of $100 \mathrm{kHz}$, and is one of the main reasons why sonochemistry and therapeutic ultrasound is performed at the low-frequency ultrasound bands of between 20 and $45 \mathrm{kHz}$.

\section{Acoustic streaming}

Analytical solutions related to acoustic streaming phenomena that occur around a vibrating sphere are available in the literature $(40,41)$. These primarily refer to the boundary layer thickness between the inner oscillatory motion and the outer acoustic streaming layer, as shown in Figure 4 and will not be discussed here in any great detail.

There is also, however, a solution for the velocity field of the outer streaming layer given by Lee and Wang (41) and this outer streaming layer can be observed experimentally (40).

4. Recent Progress in Numerical Modelling and Design 
The use of computational modelling is well reported for focussed ultrasound applications, predicting the pressure amplitudes, focused field effects and thermal effects in fluid and surrounding biological tissues. Frequencies modelled, however, are generally in the Megahertz range and with acoustic pressures predictions up to $6 \mathrm{MPa}$. For high acoustic pressure fluctuations, non-linear effects may become significant (49).

Gentry et al have studied the formation of lesions in bovine muscle by a high frequency intracardiac ultrasound ablation catheter, which uses a $10 \mathrm{MHz}$ ring transducer for ablation(50), and have developed a finite element model to predict lesion size based on temperature distribution. No computational models for predicting lesion or damage formation are yet available, however, for high power, low frequency ultrasound wire waveguide procedures, despite the recent emergence of such medical devices.

Gavin et al originally contributed a finite element model of a slender rod subject to high frequency mechanical displacements at the proximal end, and presented predictions of the effect of wire length on distal output (peak-peak displacements). The model predictions were validated by comparison with experimental measurements made using an optical microscope. Figure 7(a) shows experimental measurements and finite element analysis predictions of the distal output peak to peak displacement amplitude for a range of wire waveguide lengths. This graph reveals the critical dependence of output on wire length, and also illustrates the usefulness of the numerical model for waveguide design. Figure 7(b) shows the peak to peak displacement amplitude at locations along the length of the wire waveguide, also well predicted by the model.

This study also considered the effect of the damping characteristics of the wire, and showed that the NiTi wire waveguides exhibited significant damping over waveguides of approximately 300 $\mathrm{mm}$ length, consistent with a damping factor of $4.5 \%$. In later work, an acoustic fluid structure 
interaction finite element model of the waveguide and surrounding fluid was developed which accounted for the interaction of the wire distal tip with the surrounding fluid, and also provided predictions of acoustic pressure in the fluid at the distal tip

Gavin et al present an acoustic fluid-structure model of a therapeutic angioplasty device that can predict the pressure amplitudes in the fluid field surrounding a vibrating waveguide tip $(51,52)$. The coupled fluid structure acoustic model assembles the following matrices of equations, where the $\mathrm{M}$ and $\mathrm{K}$ matrices represent mass and stiffness matrices for the solild (subscript $S$ ) and the fluid (subscript $F$ ) respectively.

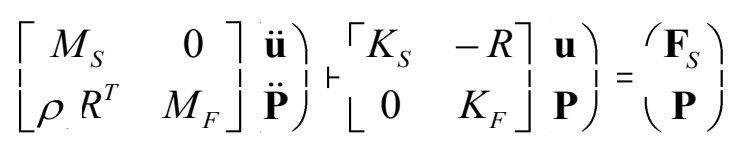

The $\boldsymbol{u}$ and $\boldsymbol{P}$ vectors represent nodal displacements and pressures respectively, and the $R$ matrices are coupling matrices representing an effective area associated with each node.

The model is capable of predicting the effect of waveguide geometry changes, such as wire length, on the instruments resonant response, and on the transmission of acoustic energy to the surrounding fluids.

Figure 8 (a) shows the predicted acoustic pressure field around the distal tip of a wire waveguide with a $1.0 \mathrm{~mm}$ diameter ball tip, and Figure 8 (b) shows a comparison with published results for that configuration. This supports the validity of the finite element model for predicting acoustic pressure fields generated by the waveguide, which is relevant to the determination of the onset of cavitation. Figure 9 (a) illustrates visually the fluid (water) response at various peak to peak displacements, showing cavitation developing from around $63 \mu \mathrm{m}$ peak to peak displacement. Based on a cavitation threshold of $2.5 \mathrm{~W} / \mathrm{cm}^{2}$, this agrees with the predictions of the numerical 
model. Figure 9 (b) shows a visualisation of the acoustic streaming phenomenon. The present form of the numerical model does not have the capability to predict this effect.

\section{Device Performance Characterisation and Validation}

\section{V.A. Transmission of ultrasound delivered via wire waveguide}

While the theoretical analysis discussed provides valuable insight to the mechanics of ultrasound transmission via wire waveguide and through surrounding fluids, they are of limited use in analysing complex geometries and conditions.

The use of the finite element method may be of benefit in assessing effects such as the inclusion of specific distal-tip geometries on the waveguide, material damping in the waveguide and ultimately the modelling of various distal-tip shapes and their effects on the surrounding acoustic pressure field developed, with consequences for the ablation mechanisms

Further, the method may be applied to the coupling of the waveguide and surrounding fluid and modelling the acoustic fluid-structure behaviour of the system. No previous modelling of therapeutic ultrasound in small diameter wire waveguides or the coupling with a distal-tip fluid appears in the literature. This technique, however, has been used in the modelling of ultrasonic acoustic horns (53).

\section{V.B. Mechanical performance evaluation}

Gavin et al (51) measured distal-tip displacements for short $1.0 \mathrm{~mm}$ diameter wire waveguide optically using a microscope with a magnification of 40 (Figure 4). This was carried out over various power inputs setting of the generator. 
Gavin et al (54) examined the $1 \mathrm{~mm}$ diameter wire waveguides over multiple lengths and each length was tested at various power level settings. It was found that as the power input is increased then the output peak-to-peak displacement is also increased. This is not true for all wire waveguide lengths; some lengths result in poor or no transmission

The study suggests that the resonant length of the wires affects the transmission. Wire waveguide lengths were examined between 118 and $303 \mathrm{~mm}$ at intervals of $5 \mathrm{~mm}$ and again using the $1 \mathrm{~mm}$ diameter wire waveguides at a constant power setting input.

The study shows that the wire waveguide has specific resonant and anti-resonant lengths. These results also showed stable ultrasound transmission was attained at anti-resonant lengths. The performance decreases as the wire length approaches resonant lengths, for the same power input.

\section{V.C. Prototypes and Clinical Devices}

Ariani et al used an ultrasound waveguide to disrupt human thrombus in vitro and in vivo(38). While no exact mode of disruption is determined their results show an inverse relationship between acoustic horn distal-tip power and time to dissolve the clots; higher powers dissolved the clots in a shorter time period.

Other authors have published similar results in the treatment of thrombus both in vivo and in vitro $(32,55)$.

In addition to this experimental work conducted on thrombus other authors have tested the effect of the ultrasound delivery on atherosclerotic lesions. Siegel et al (29) experimentally tested a $19.5 \mathrm{kHz}$ system on 50 lesions of which $34 \%$ were calcified. The results showed that ultrasound delivered via a wire waveguide could recanalise the arteries affected by the lesions 
and that the calcified arteries treated with therapeutic ultrasound could subsequently be dilated at lower pressures than before suggesting an overall increase in the distensibility of the lesion.

This effect is further supported by work conducted by Demer et al (28) when the distensibility of calcified lesions was shown to increase following ultrasound delivery. This was assessed by pressure-volume inflation curves from a standard dilation catheter as shown in Figure 10. Following the administration of ultrasound the inflation curve shifted to the right indicating increased distensibility and allowed standard balloon dilation at lower pressures.

This increase in distensibility is thought to be further increased during intervention and immediately afterwards by a phenomenon called vasodilation; the relaxation of the fibres in arteries in the vicinity of low frequency ultrasound (37). This is thought to be a biological response and beyond the scope of this work but its effects are worth noting.

\section{V.D. Patent Literature}

This section is not intended to cover all patents but rather to give an oversight of the main technical design issues and to show technical progression and suggested solutions. The overall external electromechanical systems are similar, resulting from earlier technology, requiring an ultrasonic generator, transducer (piezoelectric or magnetostrictive) and acoustic horn attached to some small diameter waveguide effectors for insertion into the body. In addition, many other design concepts are also patented from pulse mode operation to user interfaces etc.; these are considered peripheral and will not be covered in detail.

Early patents such as that obtained by Balamuth(56) describes a device that utilises ultrasonic energy for the removal of warts, tumours and skin cancer but makes no mention of operating within blood vessels. Kuris (57) obtained one of the earliest patents to disclose the use of 
vibratory displacements transmitted through a catheter inserted into a blood vessel that is surgically exposed. One of the first patents on the line to current approaches, by Boyd(58), describes the use of a semi-flexible ultrasonic vibratory catheter for the treatment of atheromas including coronary atherosclerosis. In this invention the hollow catheter itself vibrates and has a sharpened tip to facilitate the removal of tissue.

Limitations of these early patents include, open surgery, stiff transmission probes not suited to minimally invasive access, associated risks of arterial perforation and other complications. In order to overcome these, devices needed to be designed that could deliver ultrasonic vibrations via small diameter flexible waveguides (lengths approx. $1.6 \mathrm{~m}$ and diameters $<1 \mathrm{~mm}$ ), similar to other minimally technologies, such as balloon dilation catheters.

As a result, the focus of the detailed technical design, solutions and subsequent patents, in the area of minimally invasive ultrasound catheter systems for the ablation and disruption of arterial plaques, are in three critical areas:

1. wire waveguide design and material choice.

2. method by which the waveguide is connected to the acoustic horn.

3. wire waveguide distal-tip configuration.

Two key patents filed in 1989 describe ultrasonic angioplasty systems incorporating flexible waveguides, detailed connection methods and peripheral tip designs.

Bernstein and Rosenschein(59) describe an ultrasonic angioplasty waveguide system using an aluminium based alloy (AL-7075 etc.) for the waveguide material in order to reduce attenuation of the ultrasonic energy over long working lengths. They state that the distal tip should preferably be 'flat'. Their method of connecting the wire waveguide to the acoustic horn uses a 
connector that applies a gripping force to the waveguide by two radially opposing grub screws. Heat shrink fitting the connector and waveguide is also mentioned.

DonMicheal, Siegel and DeCastro (60) describe an apparatus that can induce both longitudinal and transverse motions to the wire waveguide. They propose a cobalt-nickel alloy as a suitable waveguide material. It is also suggested that a bulbous (enlarged) distal-tip efficiently transfers the ultrasonic energy while reducing the risk of 'perforating the artery'. Suggested connection methods to the acoustic horn include a 'vibration fitting' but no specific details are provided. Post 1991 many patents became increasingly more detailed.

In 1995, a patent by Pflueger, Nita et al $(61,62)$ including some inventors from above (Siegel and DeCastro) proposes an ultrasonic device comprising an elongate ultrasound transmission member (including tapered waveguides) formed of one or more super-elastic alloys such as NiTi (50 at. \% Ni). A range of wire waveguide distal-tip designs are disclosed including surface finishes with grooves and dimples to enhance material disruption and cavitation. A ferrule grip was suggested as a means of connecting the waveguide to the acoustic horn. Also mentioned was using the wire waveguide in an 'over-the-wire' configuration similar to balloon angioplasty and more common interventional methods. In 1999, Levin, Rosenschein et al (63) describe a system with a waveguide comprising of a series of transitions, multiple wires in parallel and ideal transition locations based on the standing wave setup in the waveguide. Waveguides consisting of multiple materials transitioning along the length such as aluminium and titanium alloys are included.

Nita and Sarge (62) disclose an ultrasound system with wire waveguides made from a material that includes nickel (50.5 - 51.5 at.), having tapered sections and in their embodiment they 
suggest NiTi superelastic alloys. A number of connection methods and distal-tip configurations are disclosed, including a balloon to facilitate off-centre positioning of the wire waveguide distal-tip.

In 2009, Nita et al (64) describe an ultrasound catheter device for the disruption of occlusions of blood vessels. In their embodiment they describe a wire waveguide catheter system including irrigation ports for cooling of the waveguide, an 'over-the-wire' configuration and a detailed connection system to eliminate lateral movements of the waveguide near the connection point. All with the goal of reducing heat in the waveguide and increasing its longevity.

\section{Future Directions}

Much work is still required to further understand this form of ultrasound energy delivery and the subsequent affects this has on plaque material and biological response.

Regarding the fundamental principles of the process, there is a lack of clarity surrounding the relative importance of the various proposed disruption mechanisms. Work is needed to understand the conditions required to cause cavitation in blood in vivo, and to determine its importance in plaque disruption. There is also a need to isolate tissue or plaque effects due principally to acoustic streaming, and evaluate the role that this mechanism can play. Of greatest importance, perhaps, is the need to develop an understanding of the fracture behaviour of plaque caps and lipid pools under contact with a surface vibrating at low ultrasonic frequencies.

There is a need to develop a greater understanding of the mechanics of wave transmission through long, flexible wire waveguides with complex material characteristics (as exemplified by 
Nickel Titanium (NiTi) superelastic shape memory alloys). Significant damping of wave amplitude has been observed in straight NiTi wires at low ultrasonic frequencies, and the effect of tortuous pathways, necessitating significant bending, require much greater investigation with a view to controlling losses. It is essential that the distal tip vibrations can be precisely and consistently controlled by the cardiologist, and are not unduly influenced by variable factors associated with individual procedures.

The fatigue of superelastic metals under cyclic strain at low ultrasonic frequencies has not been extensively studied, even though the reliability of these devices depends on these properties. Designs must, in any case, be configured such that wire fatigue failures (more likely at locations of mechanical connection, in the experience of the authors) do not result in being unable to retrieve all the distal elements of the device.

\section{Summary}

Calcified and totally occluded arteries pose significant complications during standard balloon angioplasty interventions and stent implantations. The use of therapeutic ultrasound transmitted via wire waveguides has been shown in initial clinical testing to be capable of disrupting thrombus, calcified and fibrous plaque without significant damage to healthy arterial tissue.

Potential end clinical benefits in the use of therapeutic ultrasound delivered via small diameter wire waveguides includes increasing distensibility of calcified plaques with the potential of reducing barotraumas and restenosis rates. This technology has also the potential in crossing chronic total occlusions, therefore allowing for standard balloon angioplasty and stent implantation to be used. 
Little detailed analysis is provided on the design aspects of these devices or how ultrasonic displacements are delivered to the distal-tip of these small diameter wire waveguides at the frequencies and amplitudes required and the disruption mechanisms these cause. With the launch of products to the U.S. and European markets potentially imminent, sophisticated models for the design and optimisation of these devices are urgently required.

This challenge demands a combination of experimental and clinical investigation, and computational modelling. A validated finite element model of the mechanical behaviour of a small diameter wire waveguide and it's interaction with surrounding fluids is necessary. Any such model would prove highly beneficial in determining the crucial wire waveguide distal-tip displacements and should be capable of predicting when the highly disruptive cavitation events occur. 


\begin{tabular}{|c|c|c|}
\hline Manufacturer & Wire & $\begin{array}{c}\text { Shaft Diameter } \\
(\mathrm{mm})\end{array}$ \\
\hline Guidant & Whisper & 0.35 \\
& Pilot 50 & 0.35 \\
& Pilot 150 \& 200 & 0.35 \\
& HT Intermediate & 0.35 \\
& HT Standard & 0.35 \\
& Cross-IT 100-400 & 0.35 \\
\hline Boston Scientific & Choice PT \& PT2 & 0.35 \\
& PT Graphix \& P2 & 0.35 \\
\hline Cordis & Shinobi \& Shinobi Plus & 0.35 \\
\hline Medtronic Vascular & Persuader & 0.35 \\
& Persuader 9 & 0.35 (tip diameter 0.27) \\
\hline Abbott Vascular & Confianza & 0.35 \\
Asahi & Confianza Pro (Conquest) & 0.35 (tip diameter 0.22) \\
& Medium & 0.35 \\
& Miraclebros & 0.35 \\
\hline
\end{tabular}

Table 1: Variety of guidewires with shaft and tip diameters

\begin{tabular}{|l|l|l|l|}
\hline Study & $\begin{array}{l}\text { Frequency of } \\
\text { Operation } \\
(\mathbf{k H z})\end{array}$ & $\begin{array}{l}\text { Distal Peak- } \\
\text { to-peak } \\
\text { Displacement } \\
(\boldsymbol{\mu m})\end{array}$ & Wire Data \\
\hline $\begin{array}{l}\text { Rosenschein et } \\
\text { al [21] }\end{array}$ & 20 & $150 \pm 25$ & $\begin{array}{l}\text { Aluminium } \\
\text { Alloy Wire } \\
1.6 m m \\
\text { No Ball Tip }\end{array}$ \\
\hline Ariani et al [7] & 20 & $63.5-111$ & $\begin{array}{l}\text { Titanium Wire } \\
.72 \text { mm } \\
2 \text { mm Ball-Tip }\end{array}$ \\
\hline Demer et al & 20 & & $\begin{array}{l}\text { Titanium Wire } \\
\text {.5mm } \\
\text { [51] }\end{array}$ \\
\hline Makin et al[62] & 22.5 & $50 \pm 25$ & $\begin{array}{l}\text { Titanium Wire } \\
1.98 / 2.46 \text { mm } \\
\text { Ball-Tip }\end{array}$ \\
\hline
\end{tabular}

Table 2: Waveguide Tip Displacements from the literature 


\begin{tabular}{|l|l|l|l|}
\hline Year & Patent Number & Inventor & Assignee \\
\hline 1969 & US 3,433,226 & Boyd & Aeroprojects Inc. \\
\hline 1970 & US 3,526,219 & Balamuth & Ultrasonic Systems \\
\hline 1971 & US 3,565,062 & Kuris & Ultrasonic Systems \\
\hline 1989 & US 4,870,953 & $\begin{array}{l}\text { DonMicheal, Siegel and } \\
\text { DeCastro }\end{array}$ & - \\
\hline 1989 & WO 89/06515 & Bernstein and Rosenschein & - \\
\hline 1995 & US 5,397,301 & $\begin{array}{l}\text { Pflueger, Nita, Siegel, Bacich, } \\
\text { Bond and DeCastro }\end{array}$ & Baxter International Inc \\
\hline 1999 & US 5,971,949 & $\begin{array}{l}\text { Levin, Saltonstall, Nguyen and } \\
\text { Rosenschein }\end{array}$ & Angiosonics Inc. \\
\hline 2006 & EP 1649,817 A2 & Nita & FlowCardia Inc. \\
\hline 2009 & US 2009/0216246 & Nita, Sarge and Spano & FlowCardia Inc \\
\hline
\end{tabular}

Table 3 Patent Literature 

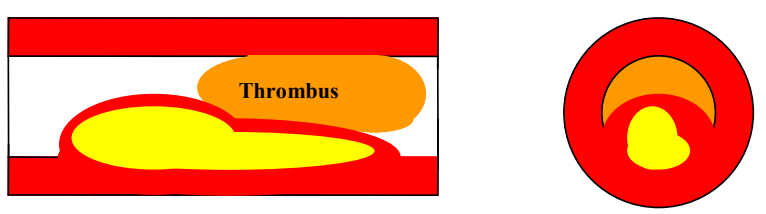

\section{Calcification}

Complicated Lesion: haemorrhage, ulceration, thrombosis
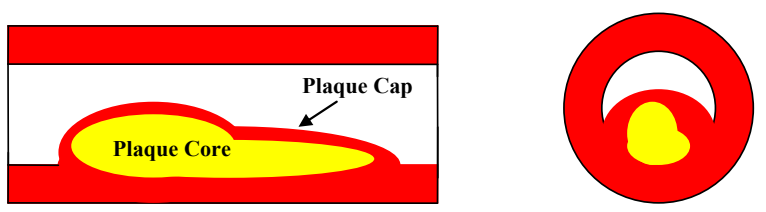

Fibrous Plaque
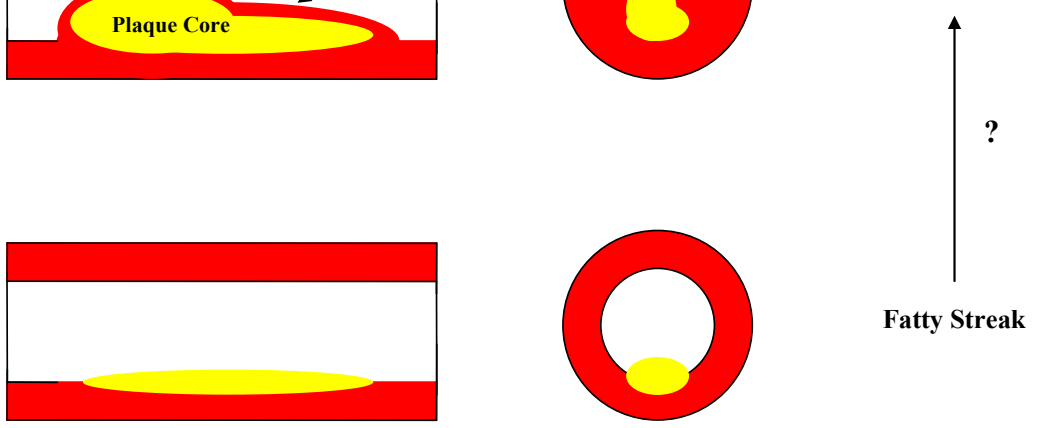

Fatty Streak

Figure 1 Progression of atherosclerosis (adapted from Salunke and Topoleski (5)). 


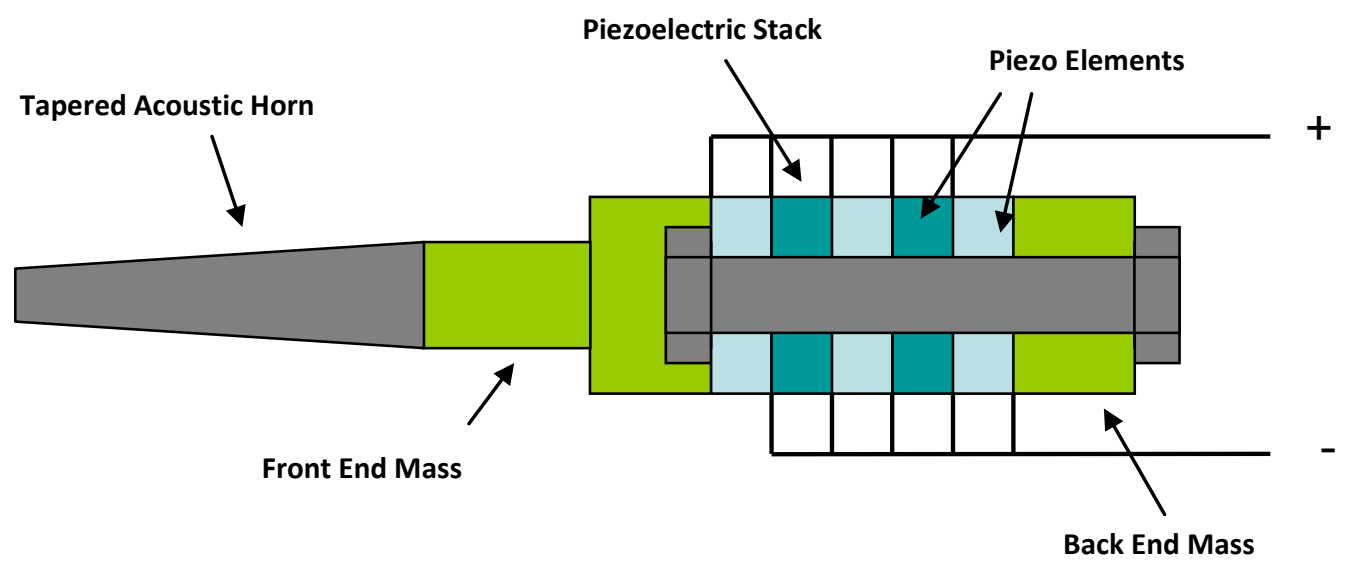

Figure 2 (a): Generation of mechanical ultrasonic displacements: converter and acoustic horn

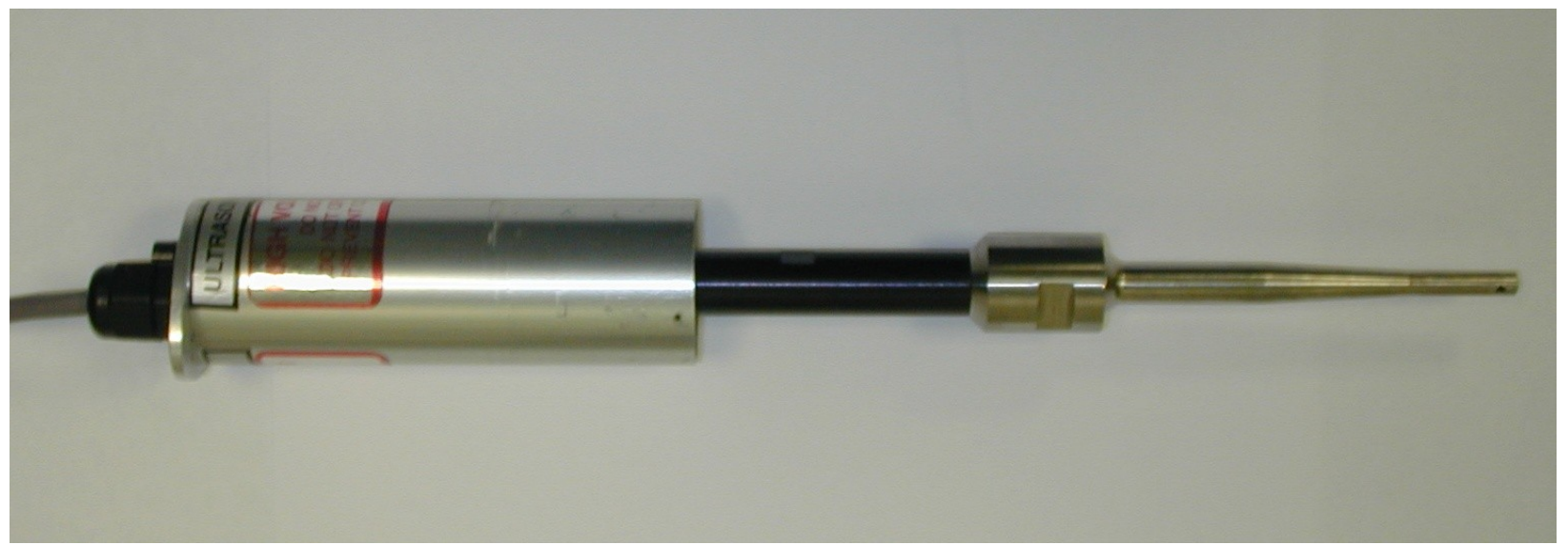

Figure 2 (b): Assembled Acoustic Horn and Converter 


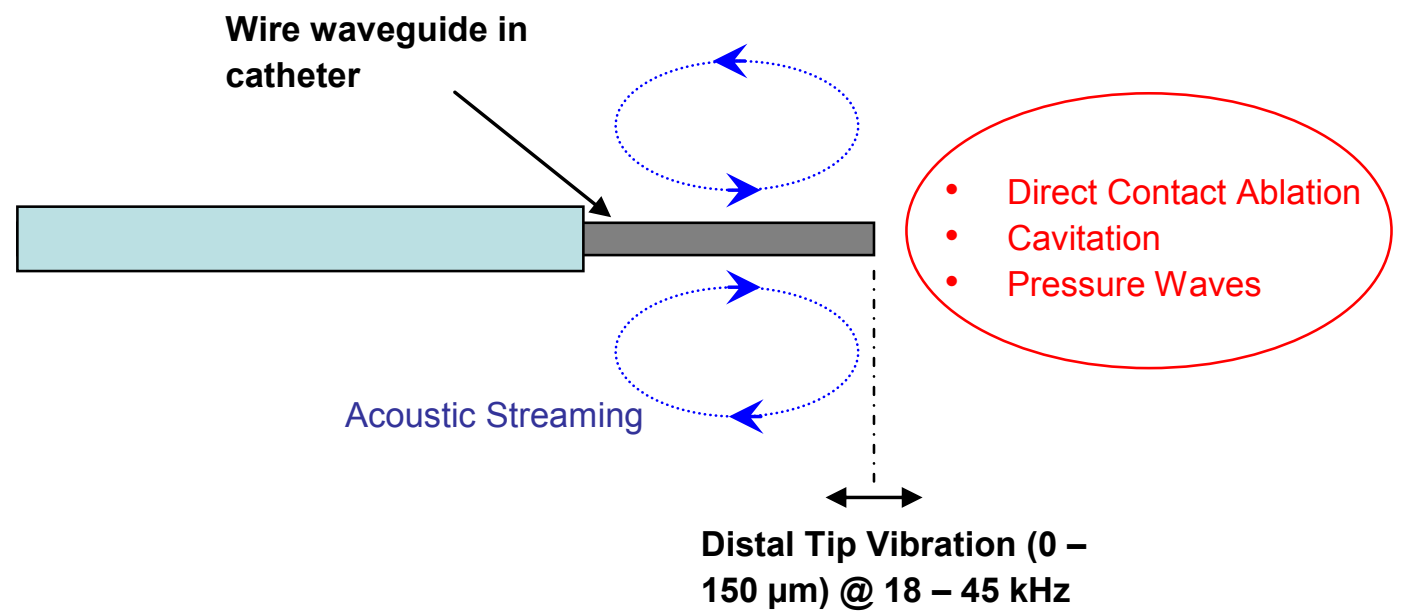

Figure 3: Schematic of ultrasonic wire waveguide in catheter and the regions surrounding the longitudinal vibrating distal-tip where disruptive mechanisms can occur.

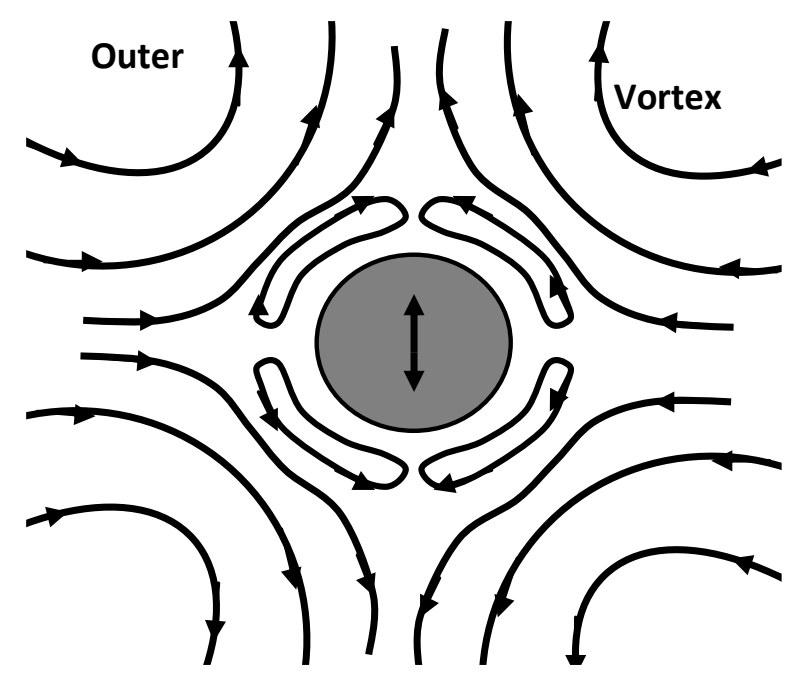

Figure 4: General features of acoustic microstreaming near a small vibrating sphere. Adapted from Nyborg (40) 


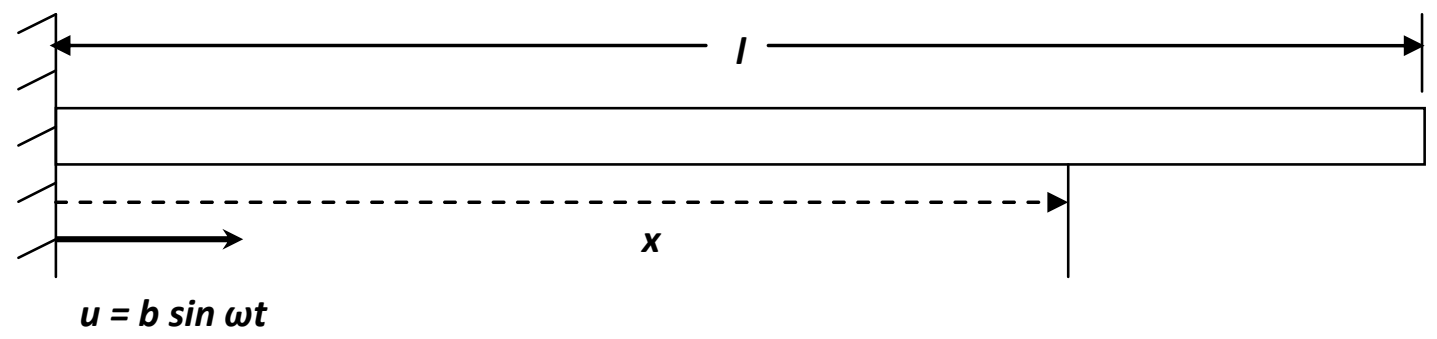

Figure 5: Diagram of a uniform rod, of length $l$, with an input displacement motion of $u=b \sin$ $\omega t$. Adapted from Steidel (47).

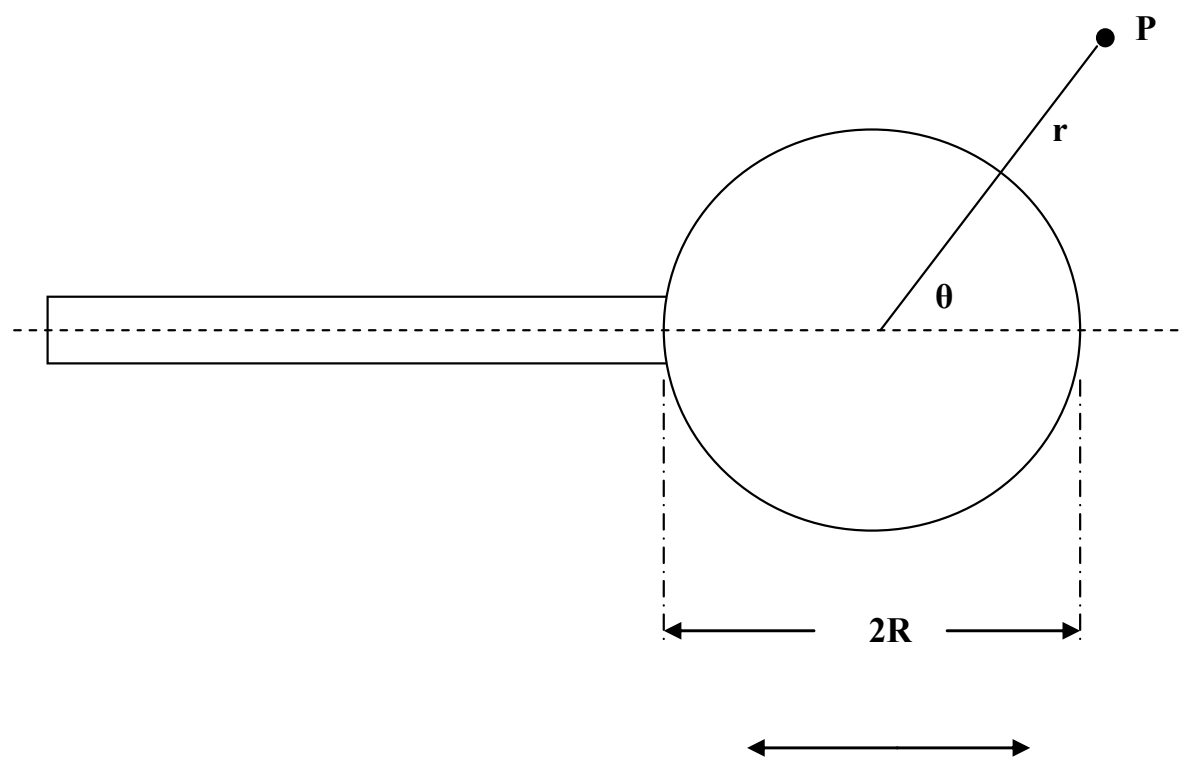

Direction of Motion

Figure 6: Diagram relating to the pressure field developed around an oscillating sphere. Adapted from Nyborg (40). 


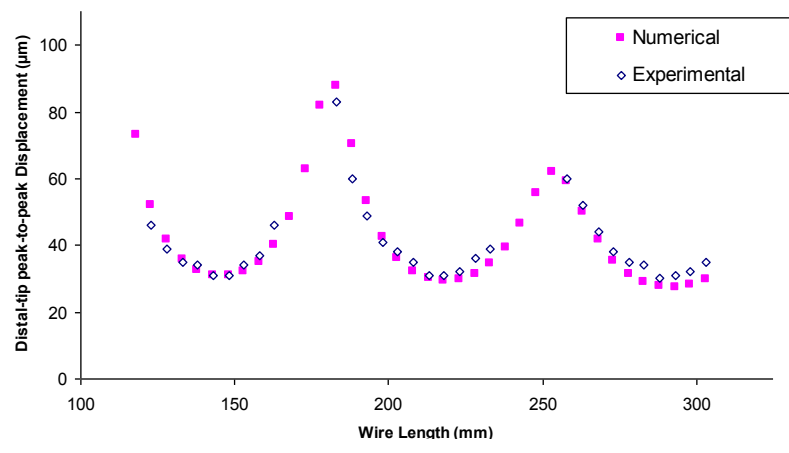

Figure 7 (a) Wire waveguide distal displacement amplitudes (51).

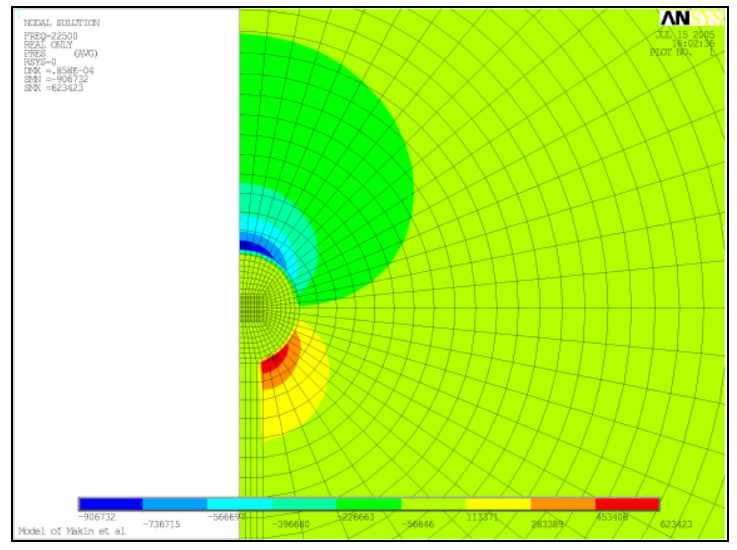

Figure 8 (a) Predicted pressure amplitude field Figure 8 (b) around the distal tip of the wire waveguide with $1.0 \mathrm{~mm}$ spherical tip.

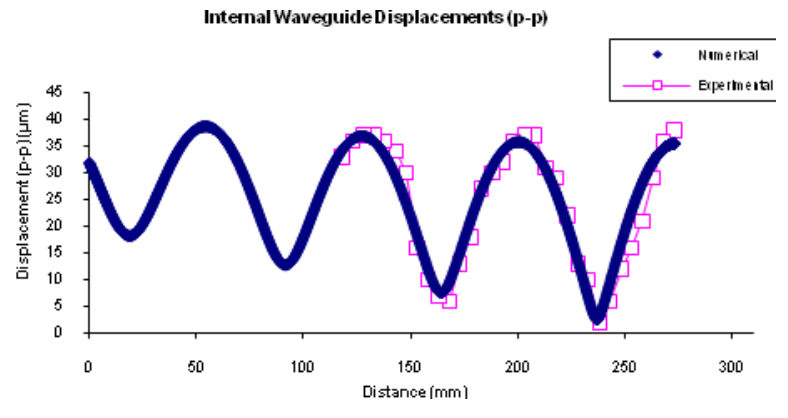

Figure 7 (b) Wire waveguide internal displacement amplitudes. (52)

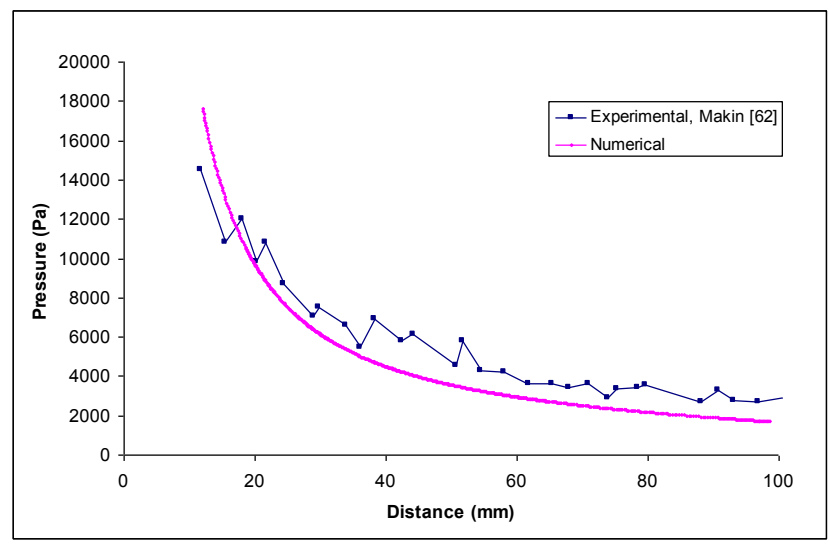

Comparison of predicted pressure amplitudes and experimental results published by Makin and Everbach (44). 


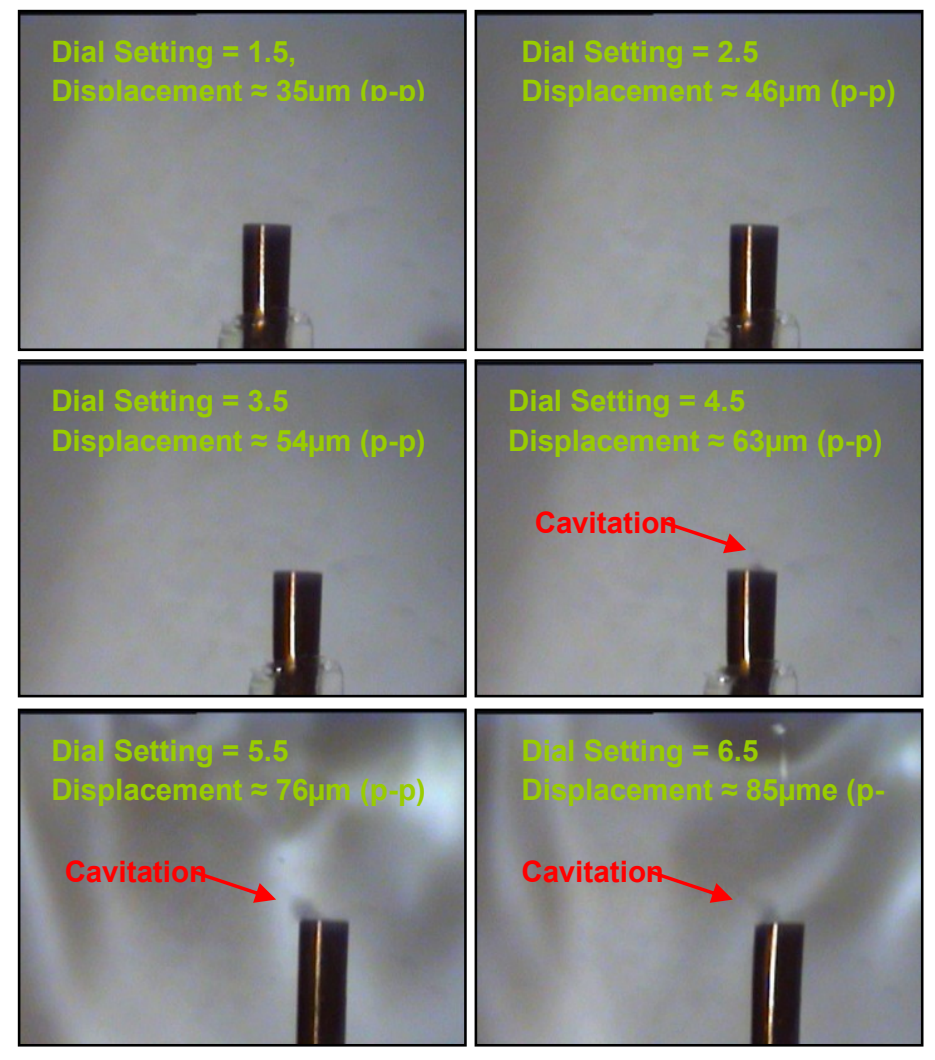

Figure 9 (a) Images of the distal tip of the $1.0 \mathrm{~mm}$ diameter wire waveguide at ambient temperature for various input power dial settings between 1.5 and 6.5. (52)

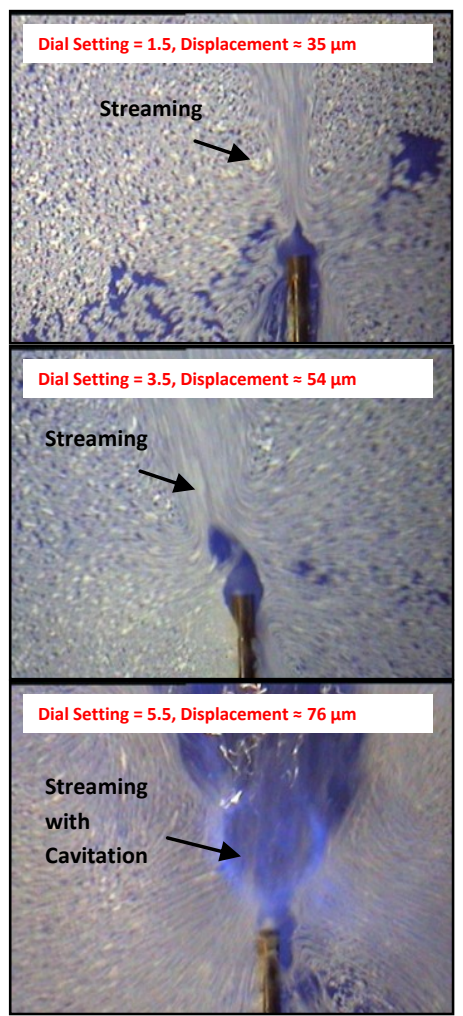

Figure 9 (b)

Acoustic streaming at distal tip (1.0 mm diameter) (52) 


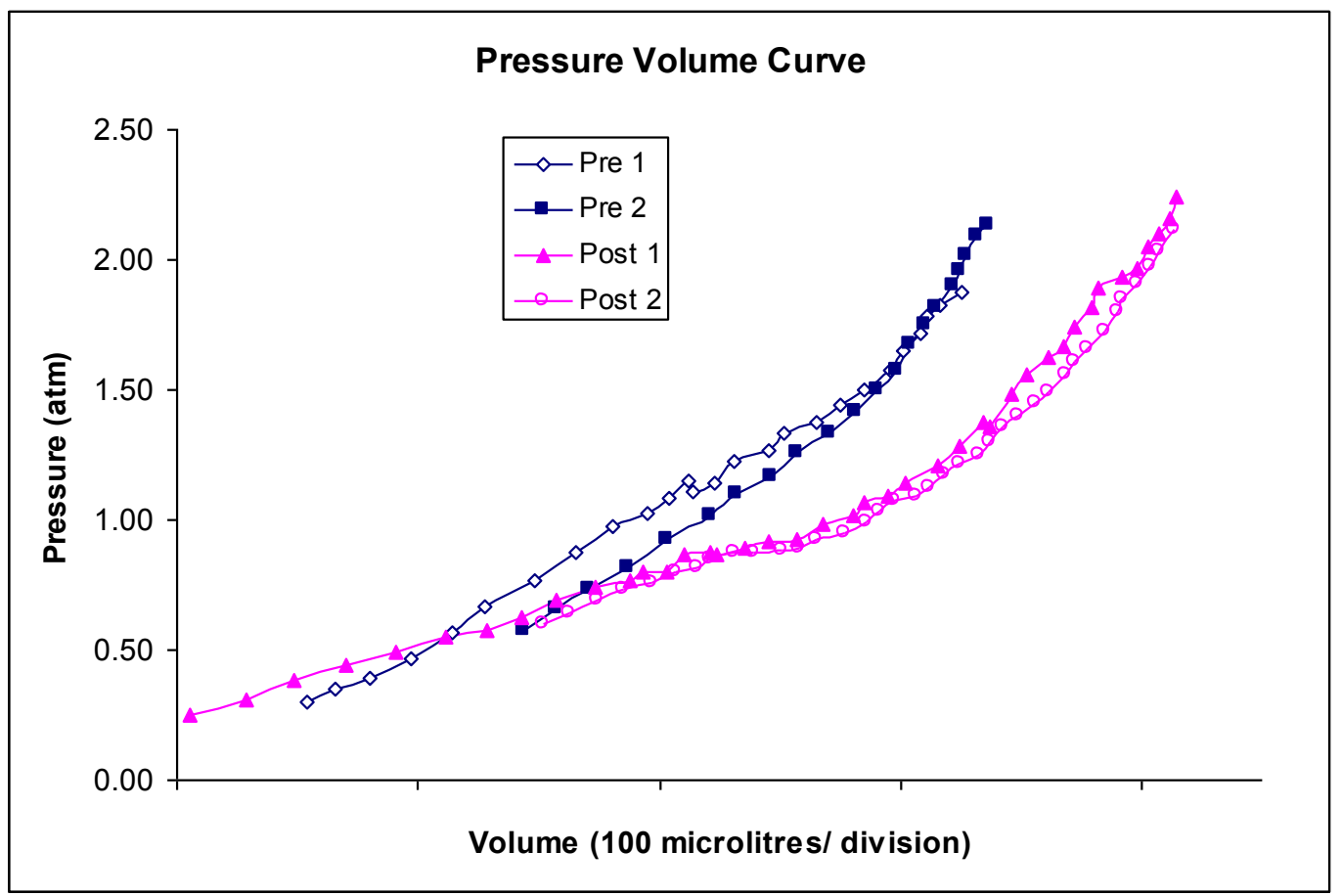

Figure 10: Example of pressure-volume curves obtained pre (left curves) and post (right curves) ultrasound energy application. The rightward shift indicates increased distensibility. Data digitised from Demer et al (28) (using xyextract $\odot$ digitising software). 


\section{References}

(1) Daria-Haust M. The natural history of human atherosclerotic lesions. Vascular Injury and Atherosclerosis: Marcel-Dekker Inc.; 1981. p. 1-24.

(2) Woolf N. Pathology of Atherosclerosis. 1st ed. London: Butterworth Scientific; 1982.

(3) Ross R. The pathogenesis of atherosclerosis--an update. N.Engl.J.Med. $1986 \mathrm{Feb}$ 20;314(8):488-500.

(4) Bouissou M, Pierragi T, Julian M. Progression, toplogical aspects and regression of atherosclerosis. In: Camilleri JP, Berry CL, Fiessinger JN, Bariety J, editors. Diseases of the Arterial Wall: Springer Verlag; 1989.

(5) Salunke NV, Topoleski LDT. Biomechanics of Atherosclerotic Plaque. Critical Reviews in Biomedical Engineering 1997;25(3):243-285.

(6) Stary HC. The histological classification of atherosclerotic lesions in human coronary arteries. In: Fuster V, Ross R, Topol EJ, editors. Atherosclerosis and Coronary Artery Disease Philadaelphia: Lippincott Williams \& Wilkins; 1996. p. 463-474.

(7) Stary HC, Chandler AB, Dinsmore RE, Fuster V, Glagov S, Insull W,Jr, et al. A definition of advanced types of atherosclerotic lesions and a histological classification of atherosclerosis. A report from the Committee on Vascular Lesions of the Council on Arteriosclerosis, American Heart Association. Circulation 1995 Sep 1;92(5):1355-1374.

(8) Loree HM, Grodzinsky AJ, Park SY, Gibson LJ, Lee RT. Static circumferential tangential modulus of human atherosclerotic tissue. J.Biomech. 1994 Feb;27(2):195204.

(9) Topoleski LD, Salunke NV. Mechanical behavior of calcified plaques: a summary of compression and stress-relaxation experiments. Z.Kardiol. 2000;89 Suppl 2:85-91.

(10) Ryan TJ, Faxon DP, Gunnar RM, Kennedy JW, King SB,3rd, Loop FD, et al. Guidelines for percutaneous transluminal coronary angioplasty. A report of the American College of Cardiology/American Heart Association Task Force on Assessment of Diagnostic and Therapeutic Cardiovascular Procedures (Subcommittee on Percutaneous Transluminal Coronary Angioplasty). Circulation 1988 Aug;78(2):486502.

(11) $\mathrm{Ng} \mathrm{W}$, Chen WH, Lee PY, Lau CP. Initial experience and safety in the treatment of chronic total coronary occlusions with a new optical coherent reflectometry-guided radiofrequency ablation guidewire. Am.J.Cardiol. 2003 Sep 15;92(6):732-734. 
(12) Aziz S, Ramsdale DR. Chronic total occlusions--a stiff challenge requiring a major breakthrough: is there light at the end of the tunnel? Heart 2005 Jun;91 Suppl 3:iii42-8.

(13) Katsuragawa M, Fujiwara H, Miyamae M, Sasayama S. Histologic studies in percutaneous transluminal coronary angioplasty for chronic total occlusion: comparison of tapering and abrupt types of occlusion and short and long occluded segments. J.Am.Coll.Cardiol. 1993 Mar 1;21(3):604-611.

(14) Stone GW, Reifart NJ, Moussa I, Hoye A, Cox DA, Colombo A, et al. Percutaneous recanalization of chronically occluded coronary arteries: a consensus document: part II. Circulation 2005 Oct 18;112(16):2530-2537.

(15) Olivari Z, Rubartelli P, Piscione F, Ettori F, Fontanelli A, Salemme L, et al. Immediate results and one-year clinical outcome after percutaneous coronary interventions in chronic total occlusions: data from a multicenter, prospective, observational study (TOAST-GISE). J.Am.Coll.Cardiol. 2003 May 21;41(10):1672-1678.

(16) Stone GW, Kandzari DE, Mehran R, Colombo A, Schwartz RS, Bailey S, et al. Percutaneous recanalization of chronically occluded coronary arteries: a consensus document: part I. Circulation 2005 Oct 11;112(15):2364-2372.

(17) Stone GW, Colombo A, Teirstein PS, Moses JW, Leon MB, Reifart NJ, et al. Percutaneous recanalization of chronically occluded coronary arteries: procedural techniques, devices, and results. Catheter.Cardiovasc.Interv. 2005 Oct;66(2):217-236.

(18) Siegel RJ, Gunn J, Ahsan A, Fishbein MC, Bowes RJ, Oakley D, et al. Use of therapeutic ultrasound in percutaneous coronary angioplasty. Experimental in vitro studies and initial clinical experience. Circulation 1994 Apr;89(4):1587-1592.

(19) Folland ED. Balloon Angioplasty. In: Topol EJ, Serruys PW, editors. Current Review of Interventional Cardiology; 1994.

(20) A finite element analysis of balloon angioplasty. Advances in Bioengineering: ASME; 1992.

(21) Oh S, Kleinberger M, McElhaney JH. Finite-element analysis of balloon angioplasty. Med.Biol.Eng.Comput. 1994 Jul;32(4 Suppl):S108-14.

(22) Godino C, Sharp AS, Carlino M, Colombo A. Crossing CTOs-the tips, tricks, and specialist kit that can mean the difference between success and failure. Catheter.Cardiovasc.Interv. 2009 Dec 1;74(7):1019-1046.

(23) Lefevre T, Louvard Y, Loubeyre C, Dumas P, Piechaud JF, Krol M, et al. A randomized study comparing two guidewire strategies for angioplasty of chronic total coronary occlusion. Am.J.Cardiol. 2000 May 1;85(9):1144-7, A9. 
(24) Melzi G, Cosgrave J, Biondi-Zoccai GL, Airoldi F, Michev I, Chieffo A, et al. A novel approach to chronic total occlusions: the crosser system. Catheter.Cardiovasc.Interv. 2006 Jul;68(1):29-35.

(25) Grube E, Sutsch G, Lim VY, Buellesfeld L, Iakovou I, Vitrella G, et al. High-frequency mechanical vibration to recanalize chronic total occlusions after failure to cross with conventional guidewires. J.Invasive Cardiol. 2006 Mar;18(3):85-91.

(26) Yock PG, Fitzgerald PJ. Catheter-based ultrasound thrombolysis. Circulation 1997 Mar 18;95(6):1360-1362.

(27) Atar S, Luo H, Nagai T, Siegel RJ. Ultrasonic thrombolysis: cattheter-delivered and transcutaneous applications. European Journal of Ultrasound 1999;9:39-54.

(28) Demer LL, Ariani M, Siegel RJ. High intensity ultrasound increases distensibility of calcific atherosclerotic arteries. J.Am.Coll.Cardiol. 1991 Nov 1;18(5):1259-1262.

(29) Siegel RJ, Gaines P, Crew JR, Cumberland DC. Clinical trial of percutaneous peripheral ultrasound angioplasty. J.Am.Coll.Cardiol. 1993 Aug;22(2):480-488.

(30) Sobbe A, Stumpff U, Trubenstein G, Figge H, Kozuchek W. Die Ultraschall-Auflosung von Thromben. Klin Wochenschr 1974;52:1117-1121.

(31) Rosenschein U, Bernstein JJ, DiSegni E, Kaplinsky E, Bernheim J, Rozenzsajn LA. Experimental ultrasonic angioplasty: disruption of atherosclerotic plaques and thrombi in vitro and arterial recanalization in vivo. J.Am.Coll.Cardiol. 1990 Mar 1;15(3):711717.

(32) Rosenschein U, Rozenszajn LA, Kraus L, Marboe CC, Watkins JF, Rose EA, et al. Ultrasonic angioplasty in totally occluded peripheral arteries. Initial clinical, histological, and angiographic results. Circulation 1991 Jun;83(6):1976-1986.

(33) Siegel RJ, Fishbein MC, Forrester J, Moore K, DeCastro E, Daykhovsky L, et al. Ultrasonic plaque ablation. A new method for recanalization of partially or totally occluded arteries. Circulation 1988 Dec;78(6):1443-1448.

(34) Wevers M, Lafaut JP, Baert L, Chilibon I. Low-frequency ultrasonic piezoceramic sandwich transducer. Sensors and Actuators A: Physical 2005;122(2):284-289.

(35) Peshkovsky SL, Peshkovsky AS. Matching a transducer to water at cavitation: acoustic horn design principles. Ultrason.Sonochem. 2007 Mar;14(3):314-322.

(36) Yang JJ, Fang ZD, Wei BY, Deng XZ. Theoretical explanation of the 'local resonance' in stepped acoustic horn based on Four-End Network method. Journal of Materials Processing Technology 2009;209(6):3106-3110. 
(37) Fischell TA, Abbas MA, Grant GW, Siegel RJ. Ultrasonic energy. Effects on vascular function and integrity. Circulation 1991 Oct;84(4):1783-1795.

(38) Ariani M, Fishbein MC, Chae JS, Sadeghi H, Michael AD, Dubin SB, et al. Dissolution of peripheral arterial thrombi by ultrasound. Circulation 1991 Oct;84(4):1680-1688.

(39) Burdic WS. Underwater acoustic system analysis. 2nd ed.: Prentice Hall; 1991.

(40) Nyborg WL. Basic Physics of Low Frequency Therapeutic Ultrasound. In: Siegel RJ, editor. Ultrasound Angioplasty. Developments in Cardiovascular Medicine: Kluwer Academic Publishers; 1996.

(41) Lee CP, Wang TG. Outer acoustic streaming. Journal of the Acoustical Society of America 1990;40:1363-1370.

(42) Morse PM. Vibration and Sound. New York: Acoustical Society of America; 1981. p. 311-326.

(43) Thoe TB, Aspiwall DK, Wise MLH. Review of ultrasonic machining. International Journal of Machine Toole and Manufacture 1998;38(4):239-255.

(44) Makin IR, Everbach EC. Measurement of pressure and assessment of cavitation for a 22.5-kHz intra-arterial angioplasty device. J.Acoust.Soc.Am. 1996 Sep;100(3):18551864.

(45) Porges G. Applied Acoustics. London: Edward Arnold; 1977.

(46) Miller DL. A Review of the Ultrasonic Bioeffects of Microsonation, Gas-Body Activation, and Related Cavitation-like Phenomena. Ultrasound in Medicine and Biology 1987:443-470.

(47) Seidel Jr. RF. Distributed Systems. An Introduction to Mechanical Vibrations. 3rd ed.: Wiley; 1989.

(48) Power Ultrasonic Equipment. Sonochemistry Symposium, Annual Chemical Congress; 8th-11th April 1986; ; 1986.

(49) Non-linear modelling of therapeutic ultrasound. IEEE Ultrasonics Symposium Proceedings; November 7th-10th 1995; ; 1996.

(50) Gentry KL, Palmeri ML, Sachedina N, Smith SW. Finite element analysis of temperature rise and lesion formation from catheter ultrasound ablation transducers. IEEE Transactions on Ultrasonics, Ferroelectrics, and Frequency Control 2005;52(10):1713-1721. 
(51) Gavin GP, McGuinness GB, Dolan F, Hashmi MSJ. Performance characteristics of a therapeutic ultrasound wire waveguide apparatus. International Journal of Mechanical Sciences 2007;49:298-305.

(52) Gavin GP, Dolan F, Hashmi MSJ, McGuinness GB. A coupled fluid-structure model of a therapeutic ultrasound angioplasty wire waveguide. Journal of Medical Devices, Transactions of the ASME 2007 December 2007;1:254-263.

(53) Use of the finite element method in ultrasonic applications. Ultrasonic Insdustry Association; June 2000; ; 2000.

(54) G. P. Gavin. Experimental and Numerical Investigation of Therapeutic Ultrasound Angioplasty. Dublin, Ireland: Dublin City University; 2005.

(55) Steffen W, Fishbein MC, Luo H, Lee DY, Nita H, Cumberland DC, et al. High intensity, low frequency catheter-delivered ultrasound dissolution of occlusive coronary artery thrombi: an in vitro and in vivo study. J.Am.Coll.Cardiol. 1994 Nov 15;24(6):1571-1579.

(56) Balamuth L, inventor. Ultrasonic Systems Inc., assignee. Method and apparatus for ultrasonically removing tissue from a biological organism. US 3,526,2191970.

(57) Kuris A, inventor. Ultrasonic Systems Inc., assignee. Ultrasonic method and apparatus for removing cholesterol and other deposits from blood vessels and the like. US $3,565,0621971$.

(58) Boyd CA, inventor. Aeroprojects Incorporated P, assignee. Vibratory catheterisation apparatus and method for using. US 3,433,2261969.

(59) Bernstein J, Rosenschein U, inventors. AnonymousSystem for angioplasty and ultrasonic contrast imaging. WO 89/065151989.

(60) Donmicheal AT, Siegel RJ, Decastro EA,. Intravascular ultrasonic catheter/probe and method for treating intravascular blockage. US 4,870,953. 1989.

(61) Pflueger R, Nita H, Bacich S, Siegel R, Bond G, Decastro E, Ultrasonic angioplasty device incorporating an ultrasound transmission member made at least partially from a superelastic metal alloy. US 5,397,3011995.

(62) Nita H, Sarge J, Device and method for supporting placement of a therapeutic device in a blood vessel. . 2005 .

(63) Levin PS, Saltonstall J, Nguyen L, Rosenschein U, Ultrasound transmission apparatus and method of using same. US 5,971,9491999. 
(64) Nita H, Sarge J, Spano R, Ultrasound catheter devices and methods. US 2009/02162462009. 